\title{
FORMAÇÃO DE MONITORES DE ALUNOS COM NECESSIDADES EDUCACIONAIS ESPECIAIS
}

\author{
Claudete Botelho Ferreira ${ }^{1}$ \\ Professora da Rede Municipal de Arroio Grande \\ http://orcid.org/0000-0002-9393-1984 \\ Bento Selau ${ }^{2}$ \\ Universidade Federal do Pampa \\ http://orcid.org/0000-0002-5792-0284 \\ Cristina Boéssio ${ }^{3}$ \\ Universidade Federal do Pampa \\ http://orcid.org/0000-0002-5792-0284
}

\section{RESUMO:}

Este texto relata uma pesquisa que procurou analisar as contribuições da formação realizada com os monitores de/para Educação Especial do município de Arroio Grande/RS, decorrentes de um processo com base no debate com os professores da escola. Tratou-se de uma pesquisa qualitativa, intervencionista, do tipo pedagógica. Os sujeitos participantes foram cinco monitores e seis professores. Para avaliar a intervenção, foram utilizadas a observação, a análise documental e as entrevistas. Como forma de analisar os dados, foi empregada a análise de conteúdo. Os resultados foram descritos por meio de três categorias: "A recepção (pedagógica) aos monitores"; "Quem orienta o trabalho do monitor? O professor"; "Os debates e as aprendizagens dos monitores". Os resultados apontam para as aprendizagens dos monitores, embora, salienta-se que seja urgente repensar uma melhor organização do processo de seleção de monitores para atuarem em Educação Especial.

Palavras-chave: Psicologia educacional. Educação inclusiva. Formação de professores. Monitores.

\section{ABSTRACT: \\ TRAINING TEACHING ASSISTANTS FOR STUDENTS WITH SPECIAL EDUCATIONAL NEEDS}

This text reports a research that aimed to analyze the contributions of the training developed with teaching assistants of Special Education from the city of Arroio Grande/RS, resulting from a process based on discussions with the school teachers. It was a qualitative, interventionist, pedagogical research. The participats were five teaching assistants and six teachers. In order to assess the intervention, observation, document analysis and interviews were used. As a way of analyzing the data, content analysis was used. The results were described through three categories: "The (pedagogical) reception to the assistants"; "Who does guide the teaching assistant's work? The teacher?"; "The teaching assistant's debates and the learning". The results point to the learning acquired by the teaching assistants, although, it is imperative to improve the recruitment process for teaching assistants.

Keywords: Educational Psychology. Inclusive education. Teacher development. Teaching assistant.

1 Mestra em Educação (UNIPAMPA). Professora da Rede Municipal de Arroio Grande. E-mail: cloferreira@gmail.com

2 Doutor em Educação (UNIPAMPA). Professor do Programa de Pós Graduação em Educação (UNIPAMPA). E-mail: bentoselau@unipampa.edu.br

3 Doutor em Educação (UFPel). Professora Adjunta (UNIPAMPA). E-mail: cristinaboessio@unipampa.edu.br 


\section{RESUMEN:}

\section{LA FORMACIÓN DE MONITORES DE ALUMNOS CON NECESIDADES EDUCATIVAS ESPECIALES}

Este texto relata una investigación que buscó analizar las contribuciones de la formación realizada con los monitores de/para Educación Especial de la ciudad de Arroio Grande/RS, decurrentes de un proceso con base en el debate con los profesores de la escuela. Se trató de una investigación cualitativa intervencionista, del tipo pedagógica. Los sujetos participantes fueron cinco monitores y seis profesores. Para evaluar la intervención, fueron utilizados, observación, análisis documental y entrevistas. Como forma de analizar los datos, fue empleado el análisis de contenido. Los resultados fueron descriptos por medio de tres categorías: "La recepción (pedagógica) de los monitores"; "Quién orienta el trabajo del monitor? El profesor"; "Los debates y los aprendizajes de los monitores". Los resultados apuntan para los aprendizajes de los monitores, sin embargo, se señala que es urgente repensar en la organización del proceso de selección de monitores para que actúen en Educación Especial.

Palabras clave: Psicología Educativa. Educación Inclusiva. Formación de Profesores. Monitores.

\section{Introdução}

A educação inclusiva deve atender às especificidades de cada criança, na coletividade. Para que isso se efetive, os envolvidos no processo escolar devem atuar de forma a colocar em prática uma proposta pedagógica que contemple o sucesso de todos. A Declaração de Salamanca aponta que o "desafio para uma escola inclusiva é o de desenvolver uma pedagogia capaz de educar com sucesso todos os alunos, incluindo aqueles com deficiência e desvantagens severas" (OREAL/UNESCO, 1994, p. 6). A necessidade de um profissional de apoio ao professor da sala regular, para atuar junto aos alunos com necessidades educacionais especiais é, logo, em diferentes situações, fundamental.

Neste contexto, a pesquisa procurou analisar as contribuições da formação realizada com os monitores de/para Educação Especial do município de Arroio Grande decorrentes de um processo baseado no debate com os professores da escola.

Mas quem é (ou pode ser) esse profissional de apoio, o monitor? Segundo uma definição do dicionário Aurélio, aluno adiantado, que ajuda, no ensino, o professor. Outras nomenclaturas são utilizadas com o mesmo intuito, como: "tutor" e "cuidador escolar". Botti e Rego, citados por Cordeiro (2017), descrevem o monitor como um tutor:

O termo tutor vem do latim oris, um termo do direito romano, atribuído àquele que se encarregava de cuidar de um incapaz. Em português, a palavra já era usada no século XIII e tinha o significado de guarda, protetor, defensor, curador; significa também aquele que mantém outras pessoas sob sua vista, que olha, encara, examina, observa e considera é o que tem a função de amparar, proteger e defender, sendo o guardião, aquele que dirige e governa (BOTTI e REGO citados por CORDEIRO, 2018, p. 18). 
No contexto desta interpretação, Cordeiro (2018, p. 18) salienta, ainda, que "o tutor é considerado um guia, um facilitador que auxilia no processo de aprendizagem centrada no aluno". Uma definição diferente aparece no texto de Farias, Pereira e Santos, (2016), no qual os autores fazem referência à expressão "cuidador escolar". Estes autores afirmam que:

O Cuidador Escolar é o profissional que está inserido na interdisciplinaridade de diversas áreas do conhecimento, para inserir o educando com necessidades educativas especiais no contexto escolar, colaborando assim, com a perspectiva da educação inclusiva. Para que fique evidenciada a importância deste profissional, apresentado um caso concreto na área de educação especial (FARIAS, PEREIRA e SANTOS, 2016, p. 04, grifos dos autores).

O monitor tem contato direto com os alunos com necessidades educacionais especiais (NEE). Ele tem a responsabilidade de mediar atividades e orientá-los em sala de aula, além de dar apoio nas práticas de higiene, alimentação, locomoção e entre outras que necessitem auxílio constante no dia a dia escolar. O monitor também é importante no que se refere à esfera emocional do aluno; por isso, ele precisa transmitir confiança a ele e à família. Como o monitor é responsável por auxiliar os alunos NEE no estreitamento das relações no espaço escolar, estar preparado para o desempenho de suas funções é fundamental, já que é sabido que o crescimento do ser humano se dá no coletivo. Por considerar importante o elo entre o monitor e o aluno com NEE, é necessário que os monitores tenham consciência de seu papel no processo educativo dos alunos por eles acompanhados e, ainda, que consigam realizar um trabalho em conjunto com o professor da sala de aula, o professor de Atendimento Educacional Especializado (AEE), bem como com os demais profissionais da escola.

Cabe afirmar que a atuação deste profissional não substitui o docente titular da turma: faz-se necessário que ambos atuem juntos e que o monitor tenha o professor como gestor da sala de aula, sendo sua primeira e principal referência, assim como o aluno com NEE. A necessidade de um planejamento em conjunto irá contribuir para o sucesso do aluno, mas a responsabilidade pelo ensino é do professor. Sobretudo, as funções que o monitor desempenha na escola devem receber a orientação do professor da sala de aula. É responsabilidade do professor determinar o que o monitor deve fazer, como e quando. Sem essa determinação, o trabalho do monitor pode ser infrutífero e acabar, inclusive, prejudicando os alunos.

No município de Arroio Grande, localizado no extremo sul do Rio Grande do Sul (RS), não há documento que defina esse profissional, nem mesmo suas atribuições nas escolas. Os monitores escolares são alunos, geralmente de ensino médio, contratados em regime de estágio remunerado, como prestadores de serviços, para atuarem nas escolas de educação básica 
do município, por meio de um convênio firmado entre a prefeitura e o Centro de Integração Empresa-Escola do RS (CIEE-RS), devidamente aprovados em um processo seletivo realizado pelo Poder Executivo.

Conforme o edital 001/2018 (PREFEITURA MUNICIPAL DE ARROIO GRANDE, 2018), o processo seletivo destina-se à formação de cadastro de reserva de estágio remunerado para atuarem em diferentes secretarias. Vale ressaltar que, dentre as vagas do processo seletivo, acima citado, estão contempladas diversas áreas: educacionais, administrativas, técnicas, da saúde, dentre outras, em nível médio ou superior. Sendo assim, é viável a contratação de profissionais que estejam cursando licenciatura. O Contrato de prestação de serviços de $n^{0}$ 02/2015, em sua cláusula 03 estabelece que:

O objetivo da contratação de serviço burocrático para manutenção e funcionalidade das atividades da Casa através de esquema de cooperação recíproca que dispõe a Lei 11.788/08 subsidiar estágios para os estudantes de ensino médio, médio técnico e superior, de interesse curricular, obrigatório ou não, entendido o estágio como uma estratégia de profissionalização que complementa o processo "Ensino Aprendizagem", conforme Projeto Básico em anexo ao processo de Dispensa 01/2015 (PREFEITURA MUNICIPAL DE ARROIO GRANDE, 2015, p. 1).

Os monitores de alunos com NEE são contratados da seguinte forma: após a realização do processo seletivo, os candidatos aprovados são selecionados pela Secretaria de Administração da Prefeitura que, por meio do levantamento das necessidades, realizado pela Secretaria Municipal de Educação (SME), designa os estagiários às escolas. Essas necessidades são encaminhadas pelas escolas à SME, no início de cada ano letivo, de acordo com a matrícula de alunos com NEE. Ao apresentarem-se na escola, os monitores são designados a atuar junto aos alunos com NEE. O critério de necessidade de apoio baseia-se no laudo médico, apresentado no ato da matrícula, pela família ou responsável, ou ainda, parecer psicopedagógico.

Ao analisar os documentos de designação dos monitores, foi possível perceber que, em sua formação, eles apenas possuíam concluído o ensino fundamental e estavam cursando o ensino médio e os cursos em andamento não apresentavam qualquer relação com a Pedagogia. Embora o processo seletivo apresente vagas para acadêmicos de Pedagogia ou outras áreas afins com a Educação, a escola onde se realizou a pesquisa, nos anos de 2017 e 2018, só recebeu monitores cursando o ensino médio, sem qualquer embasamento teórico para atuar junto aos alunos com NEE.

Considerando o conhecimento a respeito da educação inclusiva essencial para o bom desempenho dos monitores escolares do município de Arroio Grande/RS, realizou-se o plane- 
jamento, a implementação e a avaliação de uma pesquisa interventiva em uma escola da cidade. Os procedimentos metodológicos dessa pesquisa serão apresentados a seguir.

\section{Procedimentos metodológicos}

Uma proposta interventiva faz-se necessária quando, após diagnosticado um problema ou uma situação deficitária, carece de análise, estudo, ações e avaliações. No caso deste estudo, além da proposta interventiva, optou-se pela realização de uma pesquisa, a qual seguiu todo o rigor científico. Acredita-se que o professor é, ou deveria ser, um eterno pesquisador de ações pedagógicas, visando a superar os desafios do cotidiano escolar. No caso da pesquisa realizada por professores em atuação e sobre a sua própria prática pedagógica, Lüdke, Cruz e Boing (2009, p. 456) afirmam que a "possibilidade de um professor da educação básica realizar pesquisa é algo que vem suscitando significativo debate no meio universitário".

Optou-se por uma pesquisa qualitativa, intervencionista, do tipo pedagógica (DAMIANI et al., 2013). Pesquisas que adotam o procedimento da pesquisa intervencionista, do tipo pedagógica, devem descrever o plano de ação (atividades realizadas no decorrer do processo interventivo) e a avaliação da intervenção (descrição dos instrumentos da coleta de dados e procedimento de tratamento dos dados coletados). A área da Educação tem, recentemente, utilizado este procedimento com sucesso (SELAU, RODRIGUES, COSTAS e CORDEIRO, 2020; CASTRO, DAMIANI e SELAU, 2016), inclusive em teses de doutorado (PINHEIRO, 2014; ROCHEFORT, 2012).

O plano de ação escolhido para a formação foi a realização de debates a respeito de casos, na perspectiva do trabalho colaborativo, entre professores e monitores. No grupo, os participantes analisavam as situações cotidianas da educação inclusiva (os casos); havia a inclusão de excertos de teoria correlacionada, para auxiliar nas discussões.

Os casos foram sugeridos pelos pesquisadores, professores e monitores; os excertos, pelos pesquisadores. Os casos e excertos analisados nos encontros foram os seguintes:

$1^{\circ}$ CASO: Silvio (nome fictício) está no sexto ano de uma escola. Ele chegou à escola no meio do ano passado. Ele sabe reconhecer as letras e copiar as palavras, mas não consegue ler. Na última segunda-feira, sua primeira aula foi de português e, enquanto a professora explicava um exercício sobre substantivos aos demais alunos, ele fazia uma tarefa de alfabetização, acompanhado de um monitor (elaborado pelos pesquisadores).

EXCERTO: "O mesmo pode acontecer com o que ele denomina de "excitantes sociais", aqueles estímulos que provém das pessoas: o autor indica que cada pessoa pode reconstruir individualmente esses mesmos excitantes, porque se convertem em reversíveis para o próprio sujeito e determinam o comportamento de modo diferente para cada um" (SILVA JÚNIOR, 2013, p. 113). 
- $\quad 2^{\circ}$ CASO: Aluno com Deficiência Intelectual que necessitava de um monitor para realizar as atividades diárias e as avaliações. A professora de Língua Portuguesa reduzia as atividades, adaptando-as conforme o seu conhecimento, usando gravuras e aproveitando os conteúdos trabalhados. O monitor sentava-se ao lado do aluno na hora das avaliações e pelo seu despreparo, fazia toda a avaliação, deixando o aluno parado sem fazer nada e nem interagir com ninguém. A professora titular teve que intervir para que a aprendizagem e a autonomia de seu aluno não fossem mais prejudicadas (caso sugerido por uma professora).

- $\quad$ EXCERTO: "Cualquier insuficiencia corporal (...) no solo modifica la relación del hombre con el mundo, sino, ante todo, se manifiesta en las relaciones con la gente. El defecto orgánico se realiza como anormalidad social de la conducta. Incluso en el seno de la familia, el niño ciego y el sordo es sobre todo un niño especial, surge hacia él una actitud excepcional, inhabitual, que no es la misma que hacia los otros hijos. Su desgracia cambia en primer lugar la posición social en el hogar. Y esto se manifiesta no solo en las familias donde miran a ese niño como una carga pesada y un castigo, sino también en aquellas donde rodean al hijo ciego de un cariño redoblado, de una solicitud y una ternura decuplicadas. Precisamente allí, esas dosis elevadas de atención y piedad constituyen una pesada carga para el niño y una valla que lo separa de los demás (VYGOTSKI, 1997, p. 73).

- $\quad 3^{\circ}$ CASO: João (nome fictício) é um aluno muito fácil de "lidar": consegui "pegar o lado que ele mais gosta" e, muitas vezes, vou desenvolvendo um trabalho em cima disso. Vi uma palestra em que o autista sempre quer que os outros façam por ele e, em sala de aula, tirei essa conclusão. O João começou a pedir para eu apagar o que ele errou, pedia para pegar o lápis que caiu no chão, etc. (caso sugerido por um monitor).

- $\quad$ EXCERTO: “A interpretação do domínio da própria conduta feita anteriormente, com base na teoria de Vygotski, pode ser observada quando o autor se refere ao desenvolvimento da vontade na criança e no adolescente. Vygotski (1993) propõe que a atividade coletiva da criança desempenha papel central no desenvolvimento da vontade. Para o autor, todos os movimentos infantis primários que culminam em atos volitivos complexos são consequência da atividade coletiva que tem a criança. As atividades coletivas estão carregadas de motivos auxiliares por intermédio da introdução da linguagem externa que permeia toda a ação coletiva entre as pessoas" (SILVA JÚNIOR, 2013, p. 134).

- $\quad 4^{\circ}$ CASO: Manuel (nome fictício), de 07 anos de idade, que possui um diagnóstico de autismo, mora na da zona rural do município com seus pais. Este ano, foi matriculado na educação infantil da escola. Além disso, frequenta a Associação de Pais e Amigos dos Excepcionais e é acompanhado por uma psicóloga. Convive pouco com outras crianças e seu cotidiano se resume ao uso do celular, o que dificulta a sua socialização com as outras crianças, com a professora e, também, com a monitora. Sua "fissura" por equipamentos celulares é tanta que, às vezes, "avança" nas pessoas ao perceber que elas portam os aparelhos. Diversas tentativas já foram feitas pela professora e monitora, inclusive valendo-se do uso de equipamentos eletrônicos para atrair a atenção do aluno, na intenção de introduzir outras atividades, mas o esforço não está resultando em avanços (caso sugerido por uma professora).

EXCERTO: "Las condiciones sociales en las cuales debe arraigarse el niño constituyen, por un lado, todo el ámbito de su inadaptación, del cual se derivan las fuerzas creativas de su desarrollo, la existencia de obstáculos que impulsan al niño al desarrollo residen en las condiciones del ambiente social al cual debe incorporarse. Por otro lado, todo el desarrollo 
del niño es orientado al logro del nivel social necesario" (VYGOTSKI, 1997, p. 175).

$5^{\circ}$ CASO: João (nome fictício) está no $2^{\circ}$ ano do ensino fundamental e frequenta a mesma escola desde a educação infantil. O menino reconhece as letras, mas tem dificuldades em juntá-las, escrever palavras ou frases. É um menino inseguro chegando a chorar em certas situações. Sua coordenação motora fina precisa ser trabalhada. Reconhece os numerais até 10 . É um aluno calmo, mas em relação à aprendizagem, o que consegue fazer hoje, no dia seguinte não faz mais. Parece viver em um "mundinho" à parte. Na escola, João tem uma monitora exclusiva, por um período de duas horas diárias. A professora não faz atividades diferenciadas, porque o aluno gosta de fazer as mesmas atividades que os demais colegas. A professora conversou com a família sobre as dificuldades dele, que por meio do AEE, realizou o encaminhamento a um profissional da área da saúde, mas o retorno ainda não ocorreu (sugestões de uma monitora e uma professora).

- $\quad$ EXCERTO: "Hace falta crear instrumentos culturales especiales, adaptados a la estructura psicológica de ese niño, o bien llegar a dominar las formas culturales generales con ayuda de procedimientos pedagógicos especiales, porque la condición primordial y decisiva para el desarrollo cultural (...) está conservada en esos niños, su desarrollo cultural, por eso, puede recorrer caminos distintos es, en principio, completamente posible" (VYGOTSKI, 1997, p. 32).

No sexto encontro, por se tratar do último, não houve apresentação de caso: ele representou o fechamento do trabalho, com uma avaliação sobre a intervenção, realizada por todos os participantes.

Os encontros aconteceram na própria escola, em períodos fora do horário de aula. Cada encontro teve duração de $2 \mathrm{~h}$, o que totalizou $12 \mathrm{~h}$ de formação. Os sujeitos participantes foram cinco monitores (todos eles cursando o Ensino Médio) e seis professores (uma delas com contrato temporário e os demais efetivos; todos graduados em cursos de licenciatura). Para avaliar a intervenção, foram utilizadas a observação, a análise documental e as entrevistas.

Foram realizadas entrevistas do tipo semiestruturada(BOGDAN e BIKLEN, 1994) com os 5 monitores da escola, com questões relacionadas à formação, conhecimentos prévios e concepções sobre alunos com NEE, área de estudo, tipo de orientação para atuar como monitor e entendimento sobre necessidade de formação. Com 6 professores, foi realizada uma entrevista com indagações que abordaram sobre as atribuições dos monitores em sala de aula, suas possíveis contribuições e o papel que o professor exerce nessa relação.

Quanto às observações, foi escolhida a metodologia da observação participante (MARTINS, 1996), as quais perfizeram um total de seis, visto que elas aconteciam em cada encontro. Observou-se: a interação entre professores e monitores; os discursos dos participantes; a demonstração de interesse pelos assuntos abordados; as percepções, explicitadas de forma oral.

A coleta de dados ocorreu, também, por meio de conversas via recursos de mídia (WhatsApp) - instrumento análise documental. Nas análises, os registros feitos por meio do WhatsApp 
foram considerados como análise documental que, de acordo com Lüdke e André (1986, p. 38) “pode se constituir numa técnica valiosa de abordagem de dados qualitativos, seja complementando as informações obtidas por outras técnicas, seja desvelando aspectos novos de um tema ou problema". A cada encontro, alguns questionamentos foram enviados para os monitores que retornavam, logo em seguida. Como foram realizados seis encontros e eram feitos, em média, dois ou três questionamentos, por encontro, aconteciam de dezoito a vinte devolutivas no total. A análise documental (WhatsApp) ocorreu porque os monitores participantes eram muito jovens, os quais faziam uso dessa ferramenta digital com frequência. Este modo de comunicação parecia favorecer a comunicação mais do que em um grupo de estudos. A pesquisa, então, aliou-se à tecnologia, criando um grupo virtual, com a referida ferramenta, para instigar esses sujeitos a manifestarem-se de forma mais efetiva e constante.

Considerando as mídias importantes no sentido de agregar diferentes elementos às relações atuais, estreitando possibilidades de comunicação e otimizando o tempo, o uso de recursos midiáticos não pode ser negado na atual conjuntura social. Santos e Santos afirmam que:

[...] podemos pensar as tecnologias digitais como condicionantes de novas formas de agir e pensar, condicionantes de novos processos culturais, no sentido de dar condições para outras aberturas comunicacionais e educacionais. A comunicação em rede, os softwares sociais e suas interfaces caracterizam os usos dos praticantes imersos no cotidiano, nas ruas, nas praças, na universidade, nas escolas, e definem uma nova lógica comunicacional (SANTOS e SANTOS, 2012, p. 180).

Não fora deste contexto está a escola, o que justifica e fortalece o uso das mídias nos ambientes escolares.

Como forma de analisar os dados desta formação, foi utilizada a análise de conteúdo de Bardin (2009), seguindo as modificações de Moraes (2003). Esse modelo de análise foi explicado por Moraes (2003, p. 202) como "uma metodologia na qual, a partir de um conjunto de textos ou documentos, produz-se um metatexto, descrevendo e interpretando sentidos e significados que o analista constrói ou elabora a partir do referido corpus". Moraes (2003) propõe um ciclo de análise configurado em três etapas (a unitarização, a categorização e a comunicação), que se apresentam como um movimento que possibilita a emergência de novas compreensões sobre a realidade pesquisada.

\section{Achados e discussão dos dados}

Os achados foram agrupados em 3 categorias: "A recepção (pedagógica) aos monitores”; "Quem orienta o trabalho do monitor? O professor"; "Os debates e as aprendizagens dos monitores". Estas categorias serão apresentadas e discutidas na sequência. 


\section{A recepção (pedagógica) aos monitores}

O primeiro achado está diretamente ligado ao momento seguinte à contratação dos monitores (ao se apresentarem na escola para assumir suas funções). Trata-se do questionamento que surge, então: quem orienta o monitor para a realização do seu trabalho? Como se efetiva essa orientação?

Em resposta a esses questionamentos, os participantes na pesquisa, mencionaram suas percepções. A maioria dos monitores (sujeitos 1, 2, e 3) não receberam orientação para desempenhar suas funções. E, mais especificamente em relação às deficiências dos alunos, a falta de orientação apresentou-se de forma mais acentuada. O sujeito 4 (entrevista 4) afirmou que a única forma de orientação recebida para desempenhar as funções foi passada pela diretora, em rápida reunião.

Com relação à atribuição, foi comunicado para o monitor, pela supervisão da escola que, após a explicação da professora, o monitor tentasse, repetidas vezes, fazer com que o aluno entendesse a explicação da professora (sujeito 8/análise documental 6), embora nenhuma orientação de cunho pedagógica tenha sido discutida. O mesmo sujeito afirmou, também, que lhe foi dito que a professora deveria elaborar exercícios diferenciados para a aluna acompanhada por ele, todavia, o que ocorria é que a própria monitora se encarregava de fazê-los.

Outra percepção importante refere-se às concepções dos monitores com relação às suas crenças em relação aos alunos NEE, duvidando da capacidade de autonomia desses educandos. Esse equívoco ficou evidente na entrevista 3 (sujeito 4): "eu entendo assim, no meu ponto de vista assim, é uma coisa que precisa muito de apoio, porque sozinhos acredito que eles não têm muito potencial, eu vejo isso pelo que eu faço". E, indo além, havia a ideia de que um autista seria um aluno incapaz de aprender: sua presença na escola dar-se-ia apenas para se socializar, como mencionou o sujeito 7: "no começo eu pensava que, por exemplo, um aluno com autismo mais avançado não poderia progredir durante o ano, apenas estaria na escola para uma socialização" (sujeito 7/ análise documental 4).

Todas essas afirmativas revelam o desconhecimento dos monitores com relação às suas atribuições e, principalmente, o despreparo para desempenhar suas funções. Além disso, percebe-se que não havia, na escola, de forma documental e clara, a quem ou a qual setor pertencia tal responsabilidade de receber o monitor.

Freire (1996) salienta que uma educação séria precisa de embasamento teórico, mas, vai além: afirma que ela é feita de gente, gente com sentimentos, emoções a todo e qualquer instante. Esse fato jamais pode ser esquecido e saber lidar com nossas variáveis emocionais e daqueles que nos cercam, também é papel do professor. Segundo Freire:

É preciso, [...] reinsistir em que não se pense que a prática educativa vivida com afetividade e alegria, prescinda da formação científica séria e da clareza política 
dos educadores ou educadoras. A prática educativa é tudo isso: afetividade, alegria, capacidade científica, domínio técnico a serviço da mudança ou, lamentavelmente, da permanência do hoje (FREIRE, 1996, p. 161).

E, por se tratar de monitores sem qualquer formação, reforça-se o papel do poder público em ofertar uma formação inicial a esses sujeitos. No caso da escola pesquisada, tais demandas dependem do executivo municipal, do que ele considera relevante ou não, incluindo a presença dos monitores escolares. A gestão escolar fica restrita aos aspectos pedagógicos e administrativos no que se refere à estrutura de calendário escolar, desde que esteja em consonância com a SME, bem como definição de professores para cada turma e/ou disciplina.

A autonomia financeira é apenas um aspecto que deveria ser de responsabilidade do gestor escolar. Portanto, mesmo com a gestão financeira limitada, a presença de um gestor escolar é inegável, pois ele é o articulador das demais ações escolares. Conforme Luck:

A gestão escolar constitui uma das áreas de atuação profissional na educação destinada a realizar o planejamento, a organização, a liderança, a orientação, a mediação, a coordenação, o monitoramento e a avaliação dos processos necessários à efetividade das ações educacionais orientadas para a promoção da aprendizagem e formação dos alunos (LUCK, 2009, p. 23).

O gestor escolar deve ser aquele que, em parceria com toda a comunidade, articula as ações para o bom funcionamento da escola, visando sempre a atender os objetivos estabelecidos no Projeto Político Pedagógico, em consonância com a legislação vigente.

Na tentativa de cumprir a legislação, as escolas se vêm aceitando ações paliativas, sem sequer questionar e procurar entender esse processo: a substituição dos professores por profissionais com notório saber, ou pior ainda, sem o mínimo saber para atuar em sala de aula está se tornando uma constante. No discurso das exigências da inclusão escolar, essa realidade é evidente, como já foi explanado com relação aos monitores escolares.

Lasta e Hillesheim (2011, p. 95) referem-se ao discurso da inclusão escolar como "[...] uma maneira de governar/gerenciar os ditos anormais como uma forma de atingir fins úteis numa contingência histórica peculiar”. Assim sendo, destacam ainda que a educação inclusiva pode ser considerada como um:

[...] dispositivo de poder: um poder sobre a ação das pessoas, um poder que incita, constitui o que deve ser e saber e que move suas ações para a participação numa operação que não cessa até que todos sejam atingidos, atravessados e, finalmente, engajados em um modelo de sociedade que passa a existir na/ pela norma (LASTA e HILLESHEIM, 2011, p. 94). 
Nesse contexto, faz-se necessária a constante reflexão por parte de todos os envolvidos no processo escolar inclusivo com o intuito de, além de fazer valer os direitos dos alunos com NEE, buscar a efetiva inclusão, para que cada profissional envolvido tenha seu papel muito bem definido.

\section{Quem orienta o trabalho do monitor? O professor}

A pesquisa evidenciou, também, o entendimento de que o professor é o gestor da sala de aula. Tal percepção foi mencionada nas afirmações a seguir: "o professor é nosso instrutor para que possamos realizar nosso trabalho inicialmente, mas depois de já acostumado com o aluno acho que não, necessariamente, dependemos dele, mas é melhor tê-lo por perto" (sujeito 3/análise documental 5).

Já o sujeito 5 mencionou que a falta de informação e formação para atuar como monitor comprometeu o seu trabalho enquanto monitor: inicialmente, tratou os alunos como amigos e não havia uma relação de monitor/aluno; por isso, o trabalho ficou prejudicado (análise documental 12). Este participante percebeu que, em função do professor possuir formação, não passaria por esse tipo de situação. De acordo com ele:

O professor é formado no que faz, sabe lidar, de uma forma diferente, com as crianças. Nós monitores, muitas vezes no começo, começamos errado. Eu, principalmente no ano passado, tentava ser um 'amigo' dos alunos na escola, e vi que isso estava me atrapalhando profissionalmente, pois eu era um 'amigo' e não um monitor em sala de aula (sujeito 4 /análise documental 5).

Ainda com relação à gestão da sala de aula, um dos monitores afirmou que, um professor, muito provavelmente, não irá ter esse mesmo problema (sujeito 2/análise documental 12). Embora o aluno solicite ajuda do monitor, quem orienta se a ajuda ocorrerá é a professora, explicita o sujeito 3, na observação 4: "Ele me olha pedindo socorro, mas a professora é quem manda".

Muitos equívocos foram percebidos durante a pesquisa. Havia, por parte de alguns monitores, a ideia duvidosa da necessidade de atuação deles, uma vez que já havia uma professora na turma: nesse entendimento, parecia que ele era apenas uma figura decorativa. Porém, o sujeito 1 explicitou que há uma grande diferença nas atribuições da professora e dos monitores: enquanto a professora tem que desenvolver suas práticas pedagógicas de forma a contemplar todos os alunos, inclusive aqueles que têm NEE, os monitores são exclusivos de determinados alunos (análise documental 4). Portanto, cabe à professora, titular da turma, direcionar o trabalho em sala de aula, impondo-se frente às práticas pedagógicas e a rotina da aula. É o que afirma o sujeito 9: "A professora titular da turma é que tem que direcionar o trabalho" (observação 1). 
Outra ideia surgida foi que, para que o ano letivo fosse exitoso, seria imprescindível que professora e monitor estivessem em sintonia, ou seja, estabelecessem relação de parceria com unidade de trabalho. O sujeito 8 acrescentou que a criança é o foco principal do trabalho e cabe à professora e ao monitor encontrarem uma forma de trabalharem juntos, traçando metas semelhantes, com um mesmo objetivo (análise documental 7).

Com base nessas colocações, percebeu-se que o monitor precisa que o professor oriente seu trabalho, principalmente no início de suas atividades na escola. Não fosse assim, qual o sentido da formação profissional do professor?

A formação de professores prevista pela Lei n. 9394/96, no Art. 62, tem o intuito de enfrentar os desafios diários da docência. Entender essa necessidade como parte importante de um processo coletivo é fundamental e requer um comprometimento maior, inclusive do profissional do AEE, chamando para si a responsabilidade pertinente à sua função de promover, em consonância com a equipe diretiva escolar, encontros, cursos, grupos de estudos de formação continuada na escola.

A legislação brasileira vigente, referente à formação de professores para atender alunos com NEE, atende às expectativas de todos os alunos, respeitando-os nas suas individualidades e nas suas particularidades, porém, na prática há muito que se estudar para avançar. Costas e Selau, diante do exposto, afirmam:

Consequently, development programs of Special Education teachers have begun to guide inclusive education, especially since 2008. In this scenario, Vygotski's Fundamentos de defectología was supposed to be one of the main beacons of teacher education processes for Special Education, due to its revolutionary and avant-garde bias. Learning and development were understood as processes that are established collectively, corroborating the idea that "everyone can learn together", widespread by government political management and by the Special Education Department (SEESP), which was incorporated by the Citizenship Literacy Diversity and Inclusion Special Department (SECADI), in the Ministry of Education (MEC) (COSTAS; SELAU, 2018, p. 405).

Baseado nos estudos de Vygotski realizados até aqui, é possível afirmar que, por acreditar em suas concepções, em seus estudos, há uma falha muito grande no ensino brasileiro, a partir do momento em que as contribuições do referido autor são pouco estudadas. Como mesmo dizem Costas e Selau (2018), um único livro de Vygotski foi utilizado como material didático oficial no Brasil. Esse fato pode ser confirmado na prática, como já foi escrito neste texto, os professores desconhecem as contribuições de Vygotski para a educação especial, o que reafirma 
a importância da formação continuada e um estudo mais aprofundado de suas obras por ser de grande valia aos pedagogos.

\section{Os debates e as aprendizagens dos monitores}

Já que os monitores precisam de formação para desempenhar suas funções junto aos alunos com NEE, é possível fazê-la de forma isolada, sem a participação dos professores? O entendimento de que a formação deveria ocorrer com ambos os sujeitos foi decisivo para se chegar às percepções explicitadas neste artigo.

As aprendizagens dos monitores, em colaboração com os professores, foi assim sintetizada:

1. Necessidade de identificação da deficiência - A identificação da deficiência, segundo os participantes, foi considerada como ponto inicial para elaboração de estratégias de atuação. Mas, mais importante que a deficiência em si, salienta-se que é necessário reconhecer o ser humano, a pessoa, para depois pensar em estratégias compensatórias ao defeito. Vygotski afirma que:

[...] el resultado de la compensación depende no sólo de la gravedad del defecto, sino también y en gran medida, de la adecuación y eficacia de los métodos utilizados para formar los procesos compensatorios; de acuerdo con el éxito de la compensación y de la corrección se modifica la estructura del defecto (VYGOTSKI, 1997, p. 373).

2. "Monitorar" o aluno deficiente é cuidar da sua aprendizagem - Uma proposta pedagógica deve fomentar o trabalho de sala de aula, de forma com que os alunos aprendam (SELAU, RODRIGUES, COSTAS e CORDEIRO, 2020). É fundamental que, em educação inclusiva, o trabalho vá além de relações amigáveis entre alunos, instigando-se o aluno a pensar, elaborar conceitos, tomar consciência de teorias. Chama-se a atenção para o fato de que a aprendizagem é motor para o desenvolvimento psíquico de todas as pessoas, especialmente pensando em educação inclusiva:

O ensino ministrado nos ambientes educacionais, quando não memorístico, quando voltado para uma zona de desenvolvimento mais próximo do estudante é, em si, um processo que auxilia a superar as causas que geram as derivações secundárias da deficiência, isto é, o desenvolvimento incompleto das FPS (SELAU, ORTIZ e POZZOBON, 2020, p. 3).

3. Necessidade de preparo psicológico - O sujeito 8 considerou importante estar preparado psicologicamente para atuar junto aos alunos com NEE e, mais do que isso, tentar ajudá-los sem prejudicá-los (análise documental 1). Apresenta-se como exemplo a percepção do Sujeito 10: no final do ano letivo, um misto de sentimentos se fez presente neste monitor, pois alguns alunos obtiveram êxito e outros não (sujeito 10/ análise documental 1). 
4. Importância da teoria - Ficou marcado em todas as observações que o uso de teoria é fundamental para o trabalho pedagógico realizado pelo monitor e liderado pelo professor em sala de aula. Um participante mencionou a seguinte fala: "essa colocação, talvez, refira-se à zona de desenvolvimento mais próximo, de Vygotsky". Significa que a discussão do momento proporcionou uma dúvida com relação à teoria (sujeito 1, observação 5), mas, também, mostra as tentativas dos participantes de procurar compreendê-la para auxiliar nas intervenções com os alunos. A teoria fez com que houvesse a percepção de que, tanto o cuidado exagerado, como a negligência, fossem considerados fatores que podem influenciar de forma significativa, tanto positiva como negativamente (SELAU, HAMMES e DAMIANI, 2015). De acordo com o sujeito 5/entrevista 12 , as relações sociais refletem na vida do deficiente.

A teoria propiciou, também, a percepção de que o trabalho colaborativo pode ser significativo para a aprendizagem dos alunos deficientes. Foi o que afirmou o sujeito 1, na entrevista 12: "Sim, o autor diz que as pessoas podem servir de estímulo umas para as outras e eu acho que alunos com necessidades especiais vão se sentir encorajados a tentar fazer algo que não conseguem".

Nos estudos desenvolvidos nas formações, os textos utilizados em língua espanhola identificam a deficiência como defeito, embora Vygotski (1997) não o tenha feito de modo pejorativo. Os textos de Vygotski causaram estranheza, por apresentarem palavras de cunho pejorativo, porque eram mais comumente utilizadas na época da publicação de seus estudos (sujeito 10/ observação 6). O autor estudado era desconhecido de alguns participantes (embora parte deles fossem professores) e, por consequência, seus textos também eram complexos, dificultando, incialmente, o diálogo.

Embora a maioria dos participantes do grupo de estudos tenha feito referência à teoria como importante e significativa, a dificuldade de trabalhar com algumas das concepções de Vygotski (1997) foi perceptível. Costas e Selau (2018) já chamavam a atenção para o esvaziamento da concepção da defectologia vygotskiana nos processos de formação de professores. Esse esvaziamento prejudica o entendimento da defectologia como concepção teórica potente para o repensar das práticas em educação especial e inclusiva.

5) Necessidade de outros encontros de formação pedagógica - O entendimento de que, se ocorressem mais encontros de formação, as práticas pedagógicas poderiam ser mais eficazes, foi evidenciado na fala do sujeito 5, observação 1: “Acho que precisamos de mais encontros como estes, de reuniões". Porém, constatou-se que para que as formações se tornem relevantes, além de um tempo maior de duração, os encontros deveriam começar em um período específico, no início do ano letivo: “Acho que essa orientação deve acontecer no início do ano" (sujeito 9/ observação 2). O sujeito 9 , na observação 2 , vai além, ao afirmar que no início do ano letivo 
deveriam acontecer encontros, reuniões, atividades formativas e estas deveriam permanecer ao longo do ano letivo, tornando-se uma prática recorrente. Houve, porém, uma afirmação que causou estranheza: a negação da necessidade de ampliar aprendizagens, de novos cursos de formação: "Eu acho que não. Eu acho que eu estou fazendo um bom serviço, porque assim eles já estão desenvolvendo um monte" (sujeito 3/entrevista 8).

Embora as escolas tenham autonomia para elaborar seus calendários escolares, a formação continuada, na maioria das vezes, não parece ser pertinente, uma vez que continuam seguindo uma metodologia de trabalho individualista, com palestras oferecidas por mera transmissão de conhecimento. A significância desse tipo de atividade pode ser questionada. Além disso, é recorrente a contratação, por alguns municípios, de profissionais que não são da área educacional, nem afins, para a realização de um trabalho que deveria ser pedagógico e que ocorre em um curto período de tempo. Tais eventos não podem ser considerados como formativos: uma formação, para ser significativa, carece de um tempo maior, como o que é exigido num curso de mestrado, por exemplo, dois anos de muito aprofundamento teórico, aliado à investigação científica.

\section{Considerações finais}

Esta pesquisa procurou analisar as contribuições da formação realizada com os monitores de/para Educação Especial do município de Arroio Grande decorrentes de um processo baseado no debate com os professores da escola. A pesquisa proporcionou a percepção de aspectos relevantes para a atuação dos monitores junto aos alunos com NEE, o que não esgota o tema.

A formação, baseada em debates entre professores e monitores, gerou a identificação de cinco aprendizagens pelos monitores envolvidos: necessidade de identificação da deficiência do aluno a ser atendido pelo monitor; "monitorar" o aluno deficiente é cuidar da sua aprendizagem, não somente das suas relações interpessoais; necessidade de preparo psicológico para a boa atuação do monitor; importância do conhecimento de teorias pedagógicas e psicológicas para uma melhor atividade dos monitores na escola; necessidade de outros encontros de formação pedagógica.

A pesquisa proporcionou, também, a percepção da urgência de se pensar de forma mais responsável e séria a escolha dos monitores que atuam junto aos alunos com NEE em Arroio Grande, devendo esses sujeitos terem uma formação básica condizente com o desempenho das funções ou, fundamentalmente, que sejam acadêmicos da área da Educação. 


\section{Referências}

BARDIN, L. Análise de conteúdo. 4. ed. Lisboa: Edições 70, 2009.

BOGDAN, R. C.; BIKLEN, S. K. Investigação qualitativa em educação: uma introdução à teoria e aos métodos. Porto: Porto Editora, 1994.

BRASIL. Lei n. 9.394, de 20 de dezembro de 1996 - Estabelece as Diretrizes e Bases da Educação Nacional, Brasília: 1996.

CASTRO, R. F. DE; DAMIANI, M. F.; SELAU, B. Consciência e controle: uma intervenção histórico-cultural sobre a escrita de acadêmicas de Pedagogia a distância. Educação, v. 39, n. 4, p. s66-s75, 31 dez. 2016. Disponível em: https://revistaseletronicas.pucrs.br/ojs/index.php/ faced/article/view/24259 Acesso em: 27 out. 2020.

CORDEIRO. C. M. O papel do tutor no contexto da educação inclusiva: formação e dificuldades. Revista Educação em Foco, n. 9. 2017. Disponível em: portal.unisepe.com.br Acesso em: 20 de outubro de 2018.

COSTAS, F.; SELAU, B. On fundamentos de defectología and the development of Special Education teachers in Brazil. Educação, v. 41, 3, p. 401-10, Sept./Dec. 2018. Disponível em: https://revistaseletronicas.pucrs.br/ojs/index.php/faced/article/view/31865 Acesso em: 20 out. 2020.

CRUZ, G. B da; BOING, L. A; LÜDKE, M. Apesquisa do professor da educação básica em questão. Revista Brasileira de Educação. v. 14 n. 42 set./dez. 2009. Disponível em: http:// www.scielo.br/pdf/rbedu/v14n42/v14n42a05.pdf. Acesso em 10 nov. 2017/23 maio 2019.

DAMIANI, M. F. Entendendo o trabalho colaborativo em educação e revelando seus benefícios. Educar, Curitiba, n. 31, p. 213-230, 2008. Editora UFPR.

DAMIANI, M. F.; ROCHEFORT, R. S.; CASTRO, R. F.; DARIZ, M. R.; PINHEIRO, S. S. Discutindo pesquisas do tipo intervenção pedagógica. Cadernos de Educação, n. 45, p. 57-67, May/Aug. 2013. Disponível em: https://periodicos.ufpel.edu.br/ojs2/index.php/caduc/article/ view/3822 Acesso em: 14 abr. 2020.

FARIAS, A. L. P.; PEREIRA, L. G; SANTOS, W. Importância do cuidador escolar na educação de alunos com necessidades educativas especiais: da educação especial no modelo segregado a perspectiva da educação inclusiva. In: II CONGRESSO INTERNACIONAL DE EDUCAÇÃO INCLUSIVA - II JORNADA CHILENA BRASILEIRA DE EDUCAÇÃO INCLUSIVA. Campina Grande/ Paraíba: 2016. Disponível em: http://www2.unifap.br/ nai/2016/08/24/ii-congresso-internacional-de-educacao-inclusiva-ii-jornada-chilena-brasileira-de-educacao-inclusiva. Acesso em: 17 jun. 2018.

FERREIRA, Aurélio Buarque de Holanda. Dicionário Aurélio. 1 ed. Curitiba: Editora Positivo. 2011

FREIRE, Paulo. Pedagogia da autonomia: saberes necessários à prática educativa. 7. ed. São Paulo: Paz e Terra, 1996. 
LASTA, L. L; HILLESHEIM, B. Políticas públicas de inclusão escolar: a produção e o gerenciamento do anormal. In: THOMA, Adriana da Silva; HILLESHEIM, Betina. Políticas de inclusão: gerenciando riscos e governando as diferenças. Santa Cruz do Sul: EDUNISC, p. 87-108, 2011.LOPES, I de. S; G, F. E. L de; CUNHA, A. M. de O; JACOBUCCI, D. F. C. Estudos coletivos de educação ambiental como instrumento reflexivo na formação continuada de professores de ciências em espaços educativos formais e não-formais. Revista Electrónica de Enseñanza de las Ciencias. vol 10, n. 3, 516-530 (2011) Universidade Federal de Uberlândia, Brasil. Disponível em https://www.capes.gov.br. Acesso em 26 maio de 2019.

LUCK, H. Dimensões da gestão escolar e suas competências. Curitiba: Positivo, 2009.

LÜDKE, M.; ANDRÉ, M. Pesquisa em educação: abordagens qualitativas. São Paulo: EPU, 1986.

MARTINS, J. B. Observação participante: uma abordagem metodológica para a psicologia escolar. Semina: Ci. Sociais/Humanas, v. 17, n. 3, p. 266-273, set. 1996. Disponível em: <http:// www.uel.br/revistas/uel/index.php/seminasoc >Acesso em: 20 dez 2018.

MORAES, R. Uma tempestade de luz: a compreensão possibilitada pela análise textual discursiva. Ciência \& Educação, Bauru, v. 9, n. 2, p. 191-211, 2003. Disponível em: <http:// www.scielo.br/scielo.php?script=sci_arttext\&pid=S1516-73132003000200004\&lng=en\&nrm $=\mathrm{iso} \& \mathrm{t} \operatorname{lng}=\mathrm{pt} \geq$. Acesso em: 20 mai. 2021.

OREAL/UNESCO. Declaração de Salamanca e Linhas de Ação sobre Necessidades Educativas Especiais. Brasília: CORDE, 1994.

PINHEIRO, S. N. S. O jogo com regras explícitas pode ser um instrumento para o sucesso de estudantes com história de fracasso escolar? Tese (Doutorado em Educação) - Pós-Graduação em Educação, Universidade Federal de Pelotas, Pelotas, 2014.

PREFEITURA MUNICIPAL DE ARROIO GRANDE. Contrato de Prestação de Serviço. n. $02 / 2015$.

PREFEITURA MUNICIPAL DE ARROIO GRANDE. Secretaria Municipal de Administração. Edital Processo Seletivo. n.01/2018.

ROCHEFORT, R. S. Ensinar a ensinar... Aprender para ensinar! As aprendizagens na formação inicial em Educação Física nas perspectivas das Teorias Histórico-Cultural e da Atividade. Tese (Doutorado em Educação) - Pós-Graduação em Educação, Universidade Federal de Pelotas, Pelotas, 2012.

SANTOS R.S; SANTOS, E, O. Cibercultura: redes educativas e práticas cotidianas. Revista Eletrônica Pesquiseduca - p. 159-183, v.04, n. 07, jan.-jul. 2012. Disponível em: periodicos. unisantos.br > Capa > v. 4, n. 7 (2012). Acesso em: 16 dezembro. 2018.

SELAU, B.; HAMMES, L. J.; DAMIANI, M. F. Direitos humanos e preconceito a cegos universitários brasileiros. Revista Iberoamericana de Educación, v. 1, p. 103-116, 2015.

SELAU, B.; ORTIZ, K. T. D. ; POZZOBON, M. C. C. Aprendizagem de equações de primeiro grau por alunos com deficiência intelectual: possibilidades e limites. Educacao Unisinos, v. 24, p. 1-18, 2020. 
SELAU, B.; RODRIGUES, S. P.; COSTAS, F. CORDEIRO, A. Students with intellectual disabilities learning fractions: intentional pedagogical actions based on concepts of Vygotsky's defectology. Série-Estudos, v. 25, n. 54, p. 261-291, maio/ago. 2020. Disponível em: https:// www.serie-estudos.ucdb.br/serie-estudos/article/view/1402 Acesso em: 27 out. 2020.

SILVA JÚNIOR, B. S. Fatores associados à conclusão da educação superior por cegos: um estudo a partir de L. S. Vygotski. Tese (Doutorado em Educação) - Pós-Graduação em Educação, Universidade Federal de Pelotas, Pelotas, 2013.

VYGOTSKI, L. S. Obras Escogidas: Problemas de psicología geral. Madrid: Visor, 1993.

VYGOTSKI, L. S. Obras Escogidas: Fundamentos de defectología. Madrid: Visor, 1997.

Recebido: 30 de abril de 2021.

Publicado: 14 de julho de 2021. 